\title{
Chats Over Spats: Exploring Social Media Use for Mentorship in Youth Development Programs
}

\author{
JENNIFER PIERRE, University of California, Los Angeles, USA
}

\begin{abstract}
This paper presents a unique finding from a larger research project exploring social media use for social support among youth development program participants in Lafayette, IN. Through participant observation and semi-structured interviews conducted with Boys and Girls Club members ages 9-15, youth revealed varied uses of social media to sustain unexpected cross-age friendships. These friendships were perceived as integral sources of social support, and members described them to be some of the most significant in their lives at the time of their interviews. This finding raises important questions about the significant role social media may play in the maintenance of such cross-age relationships and mentorships, considering the absence of consistent face-to-face contact during the school day. Ultimately, participation in youth development programs in combination with social media use fosters these mentorships and encourages maturity and stability among these youth, which validates these unique friendships as important sources of social support. This finding offers implications for integrating digital and social media into youth development spaces, as well as for informing social and digital media designers of this particular use case.
\end{abstract}

CCS Concepts: • Human-centered computing Human computer interaction $(\mathrm{HCI})$

KEYWORDS: Youth, Social media, Mentorship, Cross-age friendship

\section{ACM Reference format:}

Jennifer Pierre. 2019. Chats Over Spats: Exploring Social Media Use for Mentorship in Youth Development Programs. Proceedings of the ACM: Human-Computer Interaction. Volume 3 Issue CSCW (November 2019), 16 pages. https://doi.org/10.1145/3359329

\section{INTRODUCTION}

On any given afternoon at Lyn Treece Boys and Girls Club, an 11-year-old facing off a 7 year old in Connect Four is a likely sight. While at first this might seem unusual, the presence of cross-age interaction is rather common in these types of non- school environments, and creates a unique opportunity for mentorship under the right circumstances. Especially for groups exposed to heightened environmental disadvantages and risk factors like those served in a variety of youth development programs, these opportunities for mentorship could pose an even more significant role in maintaining social stability [32]. These cross-age friendships can be viewed as a form of social support, an established notion in social and developmental psychology referring to feelings of self-esteem, love, and community belonging established and maintained throughout childhood and adolescence known to be a combatant against detrimental environmental risk factors [6].

Permission to make digital or hard copies of all or part of this work for personal or classroom use is granted without fee provided that copies are not made or distributed for profit or commercial advantage and that copies bear this notice and the full citation on the first page. Copyrights for components of this work owned by others than ACM must be honored. Abstracting with credit is permitted. To copy otherwise, or republish, to post on servers or to redistribute to lists, requires prior specific permission and/or a fee. Request permissions from Permissions@acm.org.

Copyright @ ACM 2019 2573-0142/2019/November - ART227 \$15.00.

https://doi.org/10.1145/3359329

PACM on Human-Computer Interaction, Vol. 3, No. CSCW, Article 227. Publication date: November 2019. 
Considering the barriers to cross-age friendship and mentorship opportunities for youth due to less traditional school based face-to-face time, alternative methods for communication and friendship maintenance like computer-mediated communication become increasingly valuable. However, this paper argues that a key part of the success and benefit of such alternative methods for sustaining cross-age friendships relies on the ease of intersecting virtual communication and existing community building spaces, which allows for both spaces to act as a combined source of social support. The body of research on cross-age friendships especially in relation to how they are maintained in these existing community building contexts is still one ripe for exploration. Though research on cross-age friendships as a phenomena is not new, and recent studies in this area provide support for the benefits of online mentorship and help define its parameters, more research on the intersection between online and offline mentoring and cross-age friendship is needed, especially within CSCW and HCI literature.

The finding presented here that youth place great significance in their cross-age friendships further motivates detailed research in this area. For all youth groups, these friendships can motivate and stimulate heightened maturity in order to strive for the friendship of older youth or fill the responsibility of caring for a younger peer [30]. The exercises in maturity building, communication, and social growth fostered by such relationships help combat the barriers and risks to successful social development and societal affiliation faced by at-risk youth. The potential value and significance of cross-age friendships for these youth groups creates an important applied benefit to better understanding the inner workings of cross-age friendships and the technologies used to support them.

This paper describes the unique mentorships and cross-age friendships built at the Lyn Treece Boys and Girls Club (BGC) in Lafayette, IN, and highlights the particular uses of digital and social media employed to form and sustain these friendships. The findings of this paper in particular assess the potential benefit of these relationships for addressing a specific mentorship oriented social support need, which can inform the design of technologies for this particular demographic of youth. This set of instances of forming and maintaining cross-age friendships and mentorships via the BGC and social media is a unique finding from a larger research project exploring the broader social media use for social support among this group.

Through participant observation and semi-structured interviews conducted with Boys and Girls Club members ages 9-15, youth revealed varied uses of social media to sustain unexpected cross-age friendships. Members described these relationships to be some of the most significant in their lives at the time of their interviews. This finding raises important questions about the significant role social media may play in the maintenance of such cross-age relationships and mentorships. Findings from this paper highlight three major overarching points: the significance of social media in supporting cross-age friendships for youth, the benefit of combining resources from existing youth development programs and social media sites as a collective source of social support, and the importance of considering cross-age friendship as a youth social media use case.

\section{RELEVANT LITERATURE}

Literature reviewed for this study briefly covers the smaller but growing body of past work investigating the connection between social media and cross-age friendships and mentorships. These works help establish an understanding of the importance of this intersection. In addition, general definitions of social media and social support are briefly provided as appropriate background for conceptualizing key concepts. 


\subsection{Key Concepts: Social Media and Social Support}

Two concepts of central interest to this study are social media and social support. Though extensive work within the HCI and CSCW community has been done in both of these areas, a brief overview of how these concepts are being considered in relation to this study is warranted. Both concepts were extensively conceptualized as part of this work in order to maintain a concrete understanding of each. Social media is identified as a key concept because it is the primary communication resource being used to maintain the cross-age friendships observed and reported. Social support is identified as a key concept because of the ultimate categorization of the friendships as a source of social support comprises its ultimate importance and impact in youths' lives.

Social support is in many ways the most difficult and intangible concept to define for this study, but it is also one of the most important and most central to this work. Cobb (1976) first coined the term as a psychological concept, defining it as "information leading the subject to believe that he or she is cared for and loved, that he/she is esteemed and valued, and he/she belongs to a network of communication and mutual obligation" (p. 300) [6]. Four main types of social support are identified in the work of Cutrona: concrete, emotional, advice, and esteem [7][8][9]. The area of social support remains a highly referenced and significant concept across a number of disciplines. In particular, a growing amount of recent literature has begun to delve deeper into discussions of the intersection of social support and marginalization as it relates to differences in race [27], economic status [29], sexuality, [25], and other related factors [3][26]. The work of Louis Leung examines the particular question of how online participation might be used as an alternative means for social support, and highlights the intersection between Internet use and social support through his research [20][21][22]. This study is aligned with Leung's approach and interest in connecting online engagement and social support as a key area of interest for HCI related disciplines. Leung's findings are understood in tandem with previous work in youth social media use [5][17][32] to frame the significant role social media can play in youth social support. The definition and sub-areas of social support were used as part of the coding process to identify references to and observations of social support exchange within the context of cross-age friendships.

One consistent definition of social media is difficult considering the rapidly changing nature of its moving parts, but marketing scholars Kaplan \& Haenlein offer a broad but applicable definition of social media as "a group of Internet-based applications that build on the ideological and technological foundations of Web 2.0, and that allow the creation and exchange of User Generated Content" (p. 61) [18]. Such foundations include public accessibility, creativity, and creation outside of professional routines. This definition has since expanded to emphasize the opportunity for collaborative relationship building, as well as further emphasize specific elements such as friend lists and user profiles [11] [28]. This definition of social media helped identify a concrete conceptualization of the different platforms that would be counted as social media for this study, which included Facebook, Snapchat, Instagram, and TikTok.

\subsection{Mentorship and Cross-Age Friendship}

As mentioned in the introduction, building spaces that facilitate cross-age friendships is not a completely new idea - foundational work in the field of elementary education has assessed the idea in various ways over the last several decades. However, the current body of traditional academic literature on cross age friendship more generally and its intersection with technology use and/or youth development programs especially in relation to social support remains sparse. 
The most comprehensive evaluation of the topic is still Smith \& Inder (1990), who found that though cross age friendships are not common, they are still present among school age children. When asked to name and nominate best friends, 35\% of interview nominated and $44 \%$ of class nominated friends reported by the youth sample were in a separate age group than them [30]. Significant findings from their work that corroborate the findings of this paper are interview reports from youth about the benefits of cross-age friendships. Youth report increased and enhanced opportunities for maturity and leadership from having friends older than them, in particular due to skill sharing and other mentoring and educational opportunities. On the other end, youth report the benefits of friendships with younger individuals to create opportunities for maturity through the development of nurturing and awareness skills that they feel they need to employ when interacting with younger friends. Dykstra and Fliecschmann (2016) similarly find a relatively small amount of cross age friendships among their sample group (18\%), but ultimately advocate for creating and sustaining opportunities for cross-age interaction [10].

Recent work in CSCW and HCI has continued to reveal beneficial uses of online spaces for mentorship and various forms of support [1] [13] [14] [15] [24]. Evans et al. (2017) identify mentorship in the form of fan fiction reviews as a major motivating factor for participation in fan fiction-focused online communities and a significant learning experience for online fan fiction writers. They find an overall willingness of reviewers to go beyond shallow comments and instead provide substantial mentorship in the writing process, contributing evidence of the benefits of distributed mentorship and building on the similar positive findings of Jenkins [17]. Ford et al. also finds strengths especially in enhancing learning experiences through an established mentorship process online [15]. In their overview of online commenting practices on Scratch, Fields et al. (2015) again find benefits to some semblance of mentorship online [14]. Despite the informal nature of the mentorship provided in this case, benefits emerge around using mentorship through commenting to help others acclimate to the community. These works help further situate research on youth development programming more broadly, for example the work Herr-Stephenson et al., within the context of youth social and digital media engagement. Such works call for continued focus on youth development programming as a prime space for integrating digital interaction [16].

Each of these works and more provide an important foundation for understanding the potential of social and digital media platforms for facilitating beneficial and influential cross-age friendship and mentorship opportunities. This paper seeks to contribute to this growing body of work, and also seeks to enhance it in the following ways: through a particular focus on social media rather than particular affinity related online social spaces, through a more in depth highlighting of cross-age friendships, and mentorship as a byproduct of such friendships rather than the sole focus, and most importantly, through a focus on the intersection between the use of these platforms and the existing space of the BGC as a combined source of social supportrelated mentorship and friendship. This intersection reveals the specifics of social support needs and benefits within this group in ways that can ideally uniquely inform the design of online social spaces for these groups.

\section{RESEARCH QUESTIONS}

The following questions used for this study were also the guiding inquiries for the larger project encompassing this work. The larger project investigated the intersection of social media and social support among at-risk youth in youth development programs, which led to the discovery 
of significant cross-age friendships as a key source of social support among this group. The significance of these questions lies in the potential application of this knowledge for the youth themselves, as well as their application in better understanding the connection between social support and social media. This understanding can ideally be used to enhance youth development programs and enhance design of social media platforms for this group. The questions are informed by the conceptualizations of social media and social support provided in the literature review, and the previous work on cross-age friendships and technology use which is framed as a potential source of social support.

These questions are additionally motivated through the theoretical framework established for the larger project that articulates the connection between social media and social support. Bowen and Chapman's theory on social support as a protective factor against detrimental elements in youths environments justifies this study's particular focus on social support as a significant resource and concept in youth development more broadly [4]. boyd's theory of networked publics motivates a fixed focus on social media as a key space for social support building [5]. These two theories combined reveal an important intersection of spaces and resources for cross-age friendships to be taking place. The youth group engaged with in this study are referred to as "at-risk" as a result of their participation in BGC youth development programming. The organization markets itself as targeting this particular population, in line with many other US-based youth development programs.

RQ1: In what ways are "at-risk" youth using social media for social support?

RQ2: What, if any, specific social support needs arise for this population as informed by their use of social media?

RQ3: How can this information inform the current scope and set of approaches for designing and implementing at-risk youth programs and activities?

This work's central assumption is that most "at-risk" youth use social media platforms for specific social support needs not entirely fulfilled in their daily lives. Assessing these needs will enable organizations like the BGC to better design their programs to meet these needs and serve their members. As demonstrated in this study, one consistent way in which youth are using social media for social support is through its use to maintain cross-age friendships and open up integral mentorship opportunities.

This particular use is the focus of this paper due to its novelty in relation to the other themes. The use of social media to sustain cross-age friendships serves a social support-based need within a context that lacks extensive face-to-face contact, unlike the other themes observed. This heightens the necessity of the technology for sustaining these relationships.

\section{METHOD}

This study used ethnographic methods to provide a descriptive and thorough report on the social life of the participants of Boys \& Girls Clubs youth development program [2]. Specifically, this study employed ethnographic practices of participant observation through establishing and sustaining a long-term relationship with the participants in their natural setting, and intensive interviewing, where the informants, or Boys \& Girls Clubs members, relayed their experiences of day to day life in the Boys \& Girls Clubs and elsewhere, their regular social media use, their feelings of social support in various contexts, and their friendships [23]. 


\subsection{Informants, Site, and Consent}

Non-probability purposive sampling of the members of the Lyn Treece Boys \& Girls Clubs of Lafayette was used to recruit 30 BGC members ages 9-15 for this study. Primary informants for this study are the 9-15 year old participants of the programs, but the five full-time staff members at the site were interviewed as part of the study as well. The total number of participants interviewed was 35 (30 youth, 5 staff). The participants were majority Black $(\mathrm{n}=16)$, followed by Caucasian $(n=11)$ and Latino/a $(n=3)$. Nine year olds comprised the largest age group $(n=14)$, followed by 10,11 , and 12 year olds $(n=5)$, and a 14 year old $(n=1)$. Females made up over half the participants $(n=22)$, followed by a small group of males $(n=8)$. The staff was comprised of three Caucasian women and two Caucasian men within the 22-35 year old age range.

The primary site for observation was the Boys \& Girls Clubs of Lafayette, IN. Entry was gained through prior contact with the club Director to gain permission to serve as a volunteer aid and to conduct the study. Consent forms were gained from both youth and adult participants as well as parents and/or guardians of youth participants prior to member participation. Considering that the majority of participants were minors, extra care was taken to follow IRB procedure and gain approval from IRB, youth participants, BGC staff and administrators, and parents before conducting the study.

\subsection{Data Collection \& Analysis}

To reflect the exploratory and descriptive aims in this study, constant comparative method was used for data collection and analysis as drawn from the grounded theory paradigm [31]. Observations occurred at the primary site for approximately six months. During each setting, in addition to assisting with various tasks as a volunteer staff aid, jotted notes were taken and developed into more detailed descriptive and reflective field notes at the end of each session, which lasts approximately 2-3 hours. Volunteer staff activities included helping run Triple Play, the required three different forms of physical activity for 30 minutes each day, distributing daily snacks, providing homework help, and helping supervise the game room and the art room. The status of the author as an authority figure was offset through the rapport building established through continued participation in daily club activities and immersion into the community. The author's unique status as not a full staff member but not an infrequent volunteer led to an amount of trust and informality that ideally enabled honest and authentic discussion and interaction.

The daily observations were carried out according to the underlying theme of immersion as described by Emerson, Fretz, \& Shaw (2011), a process where the researcher "sees from the inside how people lead their lives, how they carry out their daily rounds of activities, what they find meaningful, and how they do so" (p. 2) [12]. These notes were then analyzed through the constant comparative method and techniques of open and axial coding through line-by-line analysis and logic diagrams [23]. A similar protocol format was used for note taking and recording for up to three interviews per member lasting up to 30 minutes each over the course of the observation period. Unfortunately due to time constraints and child availability, only two youth at the Lyn Treece site were interviewed more than once.

Four major themes emerged through the data analysis process. They build on the initial open codes constructed throughout the observation period and describe the relationships and significance of the phenomena observed. These codes were administered through processes of line-by-line analysis of observation and interview documents, and axial codes were developed 
through constant comparative method and logic diagramming conducted throughout the observation period. Both groups of codes were heavily influenced by the assessment of core concepts conducted as part of the literature review. The coding schema was developed by the author and approved by a secondary researcher serving in an advisory role on the project. Observation data was viewed solely by the author, while interview data was transcribed by the author with the help of a trusted and university affiliated transcription service using temporarily stored anonymized data files.

The final four themes are a result of this layered and detailed coding process, as shown in Figure 1. The area of unique mentorships is the theme of primary focus in this study. As described in the research question section, the theme of unique mentorships is identified and highlighted as the focus of this study due to the particular needs, motivations, and constraints involved in this theme in relation to the other major themes. The whole coding schema is included here to demonstrate the general coding process and ethnographic methodology, as well as to describe how the cross-age friendship focus fits into a discussion and framing of its greater significance within the intersection of social media and social support. This paper argues that the unanticipated and novel nature of this particular theme warrants narrowed and focused discussion separate from a collective discussion of the observed themes.

Table 1: Data Analysis Coding Schema

\begin{tabular}{|c|c|c|}
\hline Open Codes & Axial Codes & Final Themes \\
\hline $\begin{array}{l}\text { Technology Use } \\
\text { - Includes all phone, tablet, and } \\
\text { computer use }\end{array}$ & $\begin{array}{l}\text { - Emotional management } \\
\text { - Technology-based friendship } \\
\text { building } \\
\text { - Setting communal } \\
\text { boundaries using technology }\end{array}$ & $\begin{array}{l}\text { Social media emotional } \\
\text { management }\end{array}$ \\
\hline $\begin{array}{l}\text { At-risk behavior } \\
\text { - Includes instances of violence, } \\
\text { hunger or other evidence of poorer } \\
\text { quality of life } \\
\text { Conflict'sép. } \\
\text { - Includes all occurrences of } \\
\text { conflict and conflict resolution }\end{array}$ & $\begin{array}{l}\text { - Rule negotiation } \\
\text { - Rule applying } \\
\text { - Punishment } \\
\text { development }\end{array}$ & Negotiated allowances \\
\hline $\begin{array}{l}\text { Social supportisép } \\
\text { - Includes all } \\
\text { displays of affection, motivation, } \\
\text { and aid }\end{array}$ & $\begin{array}{l}\text { - Social support across social } \\
\text { media and BGC } \\
\text { - Relationship management } \\
\text { using technology } \\
\text { - Communal boundary setting }\end{array}$ & $\begin{array}{l}\text { Combined constructed } \\
\text { social support }\end{array}$ \\
\hline $\begin{array}{l}\text { General notable interactions } \\
\text { - Includes all observed } \\
\text { phenomena that do not fall into } \\
\text { the previous categories }\end{array}$ & & \\
\hline
\end{tabular}




\section{FINDINGS}

In order to grasp the significance of the intersection of the Boys and Girls Club and social media for facilitating cross-age friendship and mentorship and eventual social support exchange, careful attention was paid to the established methods for facilitating mentorship and cross-age friendship at the club and social media separately and concurrently. The findings of this study describe the practices and processes at play around cross-age friendship at the BGC and online that allow for beneficial social support maintenance and exchange. The major processes and concepts at play within cross-age friendship social support exchange include the presence and encouragement of care-taking personalities, BGC structure-influenced mentorship, the articulation of key motivations of cross-age friendships, and the consistent and prevalent use of social media as a tool for supporting these aforementioned practices. These findings help depict the importance of social media as a tool for facilitating cross age friendship and mentorship, provide evidence of the intersection of the BGC and social media for cross-age mentorship based social support, and begin to provide insight into the use of social media platforms for cross-age friendship as a significant use case for interested stakeholders.

\subsection{Caretaking personalities}

Opportunities for cross-age friendship were fostered frequently through various structural protocols at the club, which facilitated the rise of particular caretaking personalities who tended to assume the role of mentorship. At the BGC, major activities like Triple Play and the art projects are done with all club members together regardless of age. The daily tournaments are no exception, where members are signed up first come first serve once the tournament is announced, and each pair is selected by reading the next two names on the sign up sheet. While this can provide challenges around non-matching skill sets, it also fosters a unique amount of cross-age collaboration that instills a sense of equal opportunity for club members. Older club members are encouraged to serve as mentors and aids when paired with younger members for activities, and often rise to the challenge. Younger members gain an extra sense of pride when succeeding at various tournaments and activities even when faced against a much older or more skilled adversary. In turn, the establishment of these cross-age social interaction opportunities creates a sense of normalcy around friendships between members of different ages and grades. Over the course of observations at the club, two personalities emerged that tended towards mentorship as well as unexpected friendships that blossomed across age gaps.

One example of the personalities that tended toward mentorship was Annabelle, a 9year-old 4th grader who was often at the center of many social circles at the club. Within the first week of observations, Annabelle consoled two club members on two separate occasions. During one, one of the youngest members, 6-year-old Kelly, ran up to Annabelle with tears in her eyes and arms outstretched for a hug, which Annabelle enthusiastically returned. Though they had not been talking before that point that day, she seemed to know that Annabelle would be available to console her, running over shortly after beginning to cry. Annabelle reacted immediately to the situation and took on a very caretaker oriented role, hugging Kelly and talking softly to her explaining that things would be okay until Kelly calmed down. This was not the first or last time Annabelle stepped up to a caretaker role, and her successes in these contexts earned her a reputation among club members as someone trustworthy to turn to and speak with about various issues. Her willingness and conscious acceptance of this role demonstrates a way that club members show social support for one another, by certain members establishing themselves as unofficial peer mentors to help their fellow club members in times of strife. 
Many staff members echoed this personality type in their interviews. When asked how they thought club members showed support for one another, three out of five staff members mentioned the way in which certain members go above what is expected of them in order to help others when they see that another member is hurt. As staff member Christian explained, "There's a few ways they will show support, but if somebody gets hurt, they'll go up to 'em. They're always wanting to be the person to take 'em up front." This pattern comes through most frequently when members volunteer to take others down to the front desk to get ice if they have been injured during a game or activity. Though a staff member or volunteer would typically bring the child up themselves following an injury, many of the older members ask to bring younger injured members up to get them ice, and that request is often granted so long as the injury is not too serious. Members seem to feel a sense of importance when doing so, and volunteer almost every time there is an injury. Staff members Nellie and Colin elaborated on this process and how it ties into a larger process of social support:

“...To see all the kids run after [one another], or somebody's sad and other kids will immediately crowd around them or come running to us to tell us what's going on, without a heartbeat, or help them. It's really cute to see some of the third and fourth graders bringing up a little kindergartener who needs to get ice and stuff like that. Or one of our fourth graders helping a first grader with their homework, or when we used to do power pages and stuff like that."

- Nellie, BGC Staff

“... When they get hurt and stuff like that, a lot of kids are willing to take them up here to help them. Like I think they... You know they do fight and stuff, it's like a family, if someone gets hurt, they'll take care of them, if some new kid's getting picked on and stuff, they look out and stuff like that. I've noticed a lot of stuff like that. They have their own little groups that... But...I mean they're happy. When we're all together and doing stuff, I think they show support and are always there for each other."

- Colin, BGC Staff

\subsection{Structure-Influenced Mentorship}

Staff member Christian noted that he is often pleasantly surprised with how much members want to step into these roles and responsibilities even when they have consistent disciplinary issues, and wants to continue to instill that sense of responsibility as a major goal of the club. The administrative staff reflects this goal in their decision to pair older and younger kids for various activities throughout the school year and summer, and through the daily inter-age mixing in tournaments, snack time, and more.

In many cases younger members and older members responded well to being paired with one another, and actively engaged in the mentor/mentee relationship. During several specially planned summer activities, older members accepted their role as mentors and teachers helping explain the activity to younger members, and younger members relied on their paired mentors to settle into the activities and complete them successfully. Staff members also showed flexibility in how members were paired, taking into consideration certain cross age friendships already in place if relevant.

Two of the oldest teens at the club during the summer, 17-year-old Andy and 14-yearold Jack, consistently signed up for Wii tournaments and stayed in the tournament area to help younger members learn how to play and set up their devices. Their willingness to help unsurprisingly did not preclude opportunities for annoyance or loss of patience, but overall 
they were able to positively teach younger members about the various Wii tournaments. In these roles members give and receive social support especially in the areas of concrete, emotional, and advice support and gain maturity and responsibility in a variety of ways.

Both parties need to demonstrate patience and respect in truly listening to each other to work together, and so they each need to ensure that both parties are heard. Older members gain the responsibility of teaching and guiding younger members, and younger members both feel supported by being taught, and give support by demonstrating appreciation for the mentorship. These relationships and opportunities then normalize cross-age communication and interaction, which encourages younger members to demonstrate the type of maturity and responsibility that fits being paired with an older member. As younger members began to familiarize themselves with various Wii tournaments, they began to branch out of their own age groups when pairing up for different rounds of the competition. By the end of the summer pairings were transcending age groups and cliques entirely, focusing instead on finding an appropriate partner for having fun playing the games.

\subsection{Motivations for Cross-Age Friendship}

Of the 30 club members interviewed, one third $(n=10)$ named a member distinctly out of their age group and grade as the friend with whom they were currently closest. The reasons given for these friends being their closest were simple, ranging from they get along well and don't fight, to they've known each other for a long time, to they help calm them down when they're feeling upset, to they just have fun together and enjoy playing at the club. None of the members seemed phased by the age difference in their interviews, instead focusing on the reasons for their friendship and how the dynamic fit into their larger social circles. Though many of these friendships were strengthened by time spent at the club, they often extended beyond that space through hangout time outside of the club and sustained conversation via social media. When asked about the older friends she had at the club and why, Marsha confirmed that she felt as close to them as her school friends and elaborated:

“... Faith is like a sister to me, and...Javi can be like a brother to me sometimes...and Rickie's like a sister to me. Then a couple of girls at school, they're like sisters to me. I can relate to a lot of people here and at school because we all like the same things, we all do the same things, we all like the same people, we all hang out with the same people. So, we all know the same people. If my best friend knows one person that I don't know, they'll be like, 'Hey, here's... This is this person, this is this person, you guys should talk.' And then we all become best friends and it's this one big, huge circle that I have here and at school."

Club member Billy named similar reasons for his friendships with older club members being most important to him, explaining:

“...Because me and him don't really get in fights a lot. We play basketball together all the time, and a little bit of soccer most of the time... And we just... we really like each other."

Though neither club member offered up long form quotes about the explicit significance of the friends they discussed, they noted the other member being discussed as their current best friend, which denotes the significance of the friendship despite age difference. As described earlier in this section, they were one of 10 members who did so. 


\subsection{Maintaining Cross-Age Friendships through Social Media}

With the exception of staff/member relationships and mentorships, members use social media as a tool for maintaining conversation and further building cross-age friendships made at the club. Among those who listed an older or younger club member as their closest friend, tools like Messenger, Snapchat, or Musical.ly are used to continue conversations started at the club, begin new ones, or make plans to spend time together in the near future.

11-year-old Lily regularly uses a Musical.ly message group with her two best friends, one older and one younger, to air grievances, talk about what has happened throughout the day, send silly images, and make plans to meet up. She particularly described the way that her use of the message group bridges her social life at the BGC and beyond:

Everyone that I have on my thing [Snapchat] know Boys and Girls Club...me and Rowan are friends on Musical.ly and so is Jessica, so we usually text on Musical.ly and I have their phone numbers, and we talk here at Boys and Girls Club.

\section{- Lily, BGC Member}

Marsha similarly uses messaging features on her accounts, primarily Instagram, to continue conversations and keep in contact with older high school friends Fiona and Josh when outside of the club. She uses the function both at the BGC when she spends time with them face-to-face, but also outside of it. She noted the importance of these spaces especially during the school year when they often don't see each other, as opposed to the summer when they spend time as a group every day at the club. Annabelle will often use her social media accounts to contact any number of friends when feeling bored and unable to hang out with friends at the moment. She described her practice of using Snapchat with friends and family older or younger than her as a way of reaching out for support:

"I probably SnapChat her the most...Like, when I'm bored. [chuckle] I need somebody to talk to. Feel lonely...or like... Oh, like when I'm sad. Sometimes I get sad because I get in trouble, so I SnapChat her and just talk to her [friend] and she calms me down.”

\section{- Annabelle, BGC Member}

The significance of using Snapchat and other accounts to maintain cross-age friendships for Annabelle is the inspiring and mentoring messages she receives return. She describes the tendency to receive responses to posts on Snapchat that encourage her to be herself and keep going. In this way her social media use also compliments her caretaking personality, where she is able to combine her role as a caretaker at the BGC with her additional role as a mentee to others online. She is able to navigate these spaces and roles freely depending on her needs at a given time. Michael echoes this kind of use, using Snapchat to maintain friendships at the club but also familial relationships with siblings or cousins much older than him.

For those who did not use social media to contact friends outside of their classes and age group, many still used digital media to connect with them through playing online games. Sharing YouTube videos was another way of communicating using social and digital media for those without accounts. Both social media and online games were also used for bonding when spending time together face to face. Members watch videos together, play games, and take Snapchats or Musical.lys face to face at the club in addition to playing tag or board games, and can then seamlessly continue the use of digital media once they are apart for the day. Having these spaces available for continued connection becomes especially important with these cross- age mentorships and friendships, where the ability to see each other consistently throughout the day in classes is removed. The strength of these relationships as some club members' closest 
friendships in spite of the availability of other friends seen more consistently throughout the day denotes their importance, and suggests that they fill a significant role in members' lives.

There is a certain honor members perceive to being able to maintain a meaningful friendship across age barriers and a certain maturity that it requires. This maturity carries over to the continued conversation and information sharing occurring on social media when face to face interaction isn't possible, to ensure that the relationship persists. This specific use of social media can be categorized as an example of boyd's (2014) distributed networks, as it is used to bridge relationship development between face-to-face interactions. However, this particular use is bridging not just a traditional peer relationship but one that signals and requires the maturity of transcending age barriers, and fills a need and desire for clear and stable mentorship and support from older or younger peers. Additionally, this work builds on previous findings in the field around mentorship online through a closer look at the affordances of online mentorship concurrent with face-to-face cross-age mentorship. This overview of cross-age friendship at the Lafayette BGC offers a more nuanced look at a more informal form of mentorship through crossage friendship, where the intersection of online and offline peer social exchange allows for positive fulfillment of social support needs.

These relationships serve as points of guidance and support in both directions, and are unique pieces of social development in the social circles of club members as they transition into adulthood. Both advice and esteem support are particularly relevant in these relationships. Perhaps it is due to the different perspectives they need to be sensitive to in a friendship of different ages, but many members find their relationships with older or younger peers to be calmer and more relaxed, as unexpected as it may seem. Billy, Marsha, and Annabelle all noted when interviewed that they appreciated these friendships in particular because they don't get into fights, and just "get each other." As Marsha importantly notes about her friend Fiona, 4 years her senior, "I've fought with every single one of my friends but her."

\section{DISCUSSION}

This paper emphasizes the significance of the BGC and social media as specifically combined sources of social support for club members through their use to facilitate meaningful cross-age friendships and mentorships. Without the delicate balance of the two, members would not have the opportunities described here to form these relationships and maintain and grow them into long-term mutual friendships. The significance these observations reveal about this combination point to the role that this knowledge can play for youth development programs more generally, as related to technology use, standards, and protocols at places like the BGC. These findings additionally create an insightful glance at a particular use of social media among youth that can influence and inform the design of these platforms.

Seeing the successful blending of offline and online social interaction displayed at the club especially to blossom these unique mentorships, presents this theme as a substantial case study contribution to the work of Herr-Stephenson et al. [16]. Like they suggest in their evaluation of the intersection of digital media and after-school youth development programs, the Lyn Treece BGC is no exception to the significant barriers faced in such programs for implementing creative and supportive technological infrastructure with which club members can engage. Besides general rules and loose policies around phone usage throughout different parts of the day, no programming is available that relates to basic technology use, navigating online spaces, and importantly, positively engaging with social media and other prevalent online spaces. However, the use of formal technological infrastructure at the club is not the only beneficial mode of 
technology use. Through the allowance of social and digital media use during free time, club staff provide members with the opportunity to craft their own personal systems and practices of technology use while using the BGC as a backdrop for broader social interaction, stimulation, and growth.

In contrast to many of the case examples Her-Stephenson et al. cite as successful implementations of digital media in youth development programs which focus on formally developed systems, this case centers on the value of flexible mentorship and informal cross-age friendships as ways to allow for personal blending of online and offline interaction. The use of social media in the examples described above to maintain cross-age friendships formed at the club are still solid examples of Herr-Stephenson et al.'s findings that youth in these settings can gain substantial knowledge and skills through participation with media. Though Lyn Treece unfortunately does not have the funds or the knowledge base to form a club based robotics team, the youth there are formulating strong and valuable skills in communication and relationship building through their blended interfacing with older and younger members, and are growing in maturity and responsibility through these processes. The youth interviewed on their cross-age relationships revealed perceptions of being supported, cared for, and loved, tying this system and blending of the BGC and social and digital media use again to a substantial demonstration of social support.

\subsection{Limitations and Implications for Future Work}

In addition to the implications these findings provide for integrating digital and social media into youth development spaces and developing protocol in such areas, this paper's findings offer a closer look at the specific mentorship-related social support needs that can inform social media design for at-risk youth. The findings here provide insight into a number of roles, practices, and specific social support related needs that can be further reflected in the platforms members are currently using.

The ways in which these youth use social media in and outside of the club, as well as their motivations for doing so, make visible the processes of expressing, building, and navigating vulnerability, trust, and personal systems of social engagement that are core to successful social support exchange. These specific needs further nuance the understanding of social support processes, in terms of how and why it is gained and received for this particular population. The success of these friendships and the value placed in them by youth continues to demonstrate the affordances of the club as a community building space that enables fruitful, creative, and autonomous social engagement and friendship building and maintenance. Within the mix of searching for space for strengthening and expressing one's network, this study also shows youth members striving for ways to address vulnerability, establish trust, and validate networks and friendships. Mentorship and cross-age friendship is a strong example of pursuing these needs especially in reaction to difficult and complex familial structures and home lives.

These overarching processes point to a number of social support-related values regarding cross-age friendship and mentorship that can be facilitated through the enhancement of both the youth development spaces and virtual spaces that youth use to achieve their goals and fulfill their support needs. Next steps for this work will center on developing recommendations for youth counselors and programmers as well as designers and other stakeholders in using this applying this knowledge to their work with youth. Key limitations of this study include the limited scope of the study through the specific BGC focus, as well as the reliance on reported uses of social media use in tandem with observed group uses of social media use without specific observation of 
individual social media platform use at length. For a variety of reasons including privacy and comfort concerns, observations did not include in-depth observation periods focused just on examining each individual's interaction with various platforms over extended periods of time. This is an area that will be explored in future work, and will ideally be more possible due to the now well-established relationships with BGC youth. The expansion of the study to multiple sites is also an important intended goal for future work.

\section{CONCLUSION}

For many at the Lyn Treece Boys and Girls Club, age is but a number when it comes to forming friendships. In the midst of everyday stressors, family troubles, and the wide-open future, more important than shared age or grade are common interests, lack of drama, and just getting along in the best sense of the phrase. The unique mentorship youth find in their friendships with older and younger members at the club push them to be the most mature versions of themselves. Whether it's assuming the responsibility of mentoring, teaching, or hanging out with someone younger, or demonstrating the ability to responsibly spend time with someone older, these relationships fill the desire for varied role models, for someone to support and care for, and for someone to support and care for them. These relationships begin through the practice of opening up opportunities for cross-age bonding and collaboration, as promoted by designed club activities that utilize member pairing and aid. The friendships that build from these collaborations are then threaded together into members' broader social circles through social and digital media, which provides the means for communicating in between face- to-face moments and ensures continued conversation and bonding even without the usual means of daily classes and school time together. This process highlights the significant role social media is playing in tandem with the BGC for providing social support through cross-age friendship opportunities, and provides evidence of a particular social media use case for meeting these particular social support needs related to mentorship and guidance.

The process of developing and maintaining unique mentorships at the Boys \& Girls Club and the role that social and digital media plays in their sustained development presents both of these spaces combined as a significant and unique source of social support for club members. Both places act as an important piece of the overall communication cycle of youth members in perceiving, seeking, and gaining social support from various groups and individuals in their lives. Whereas the infrastructural allowances and opportunities for cross-age friendship development provided at the club often initiate these mentorship and friendship instances, they are sustained and maintained through frequent social and digital media interactions, which help solidify these friendships as significant ones. These club and media spaces together provide a specific source of consistent support and motivation for successful transitions into adolescence and adulthood, by motivating new social experiences and opportunities and melding perspectives that will help guide members as they grow. The focus on the intersection of the BGC and social media provided in this paper and the identification of elements and affordances of each that facilitate positive cross-age friendships will help inform varied stakeholders in youth support and youth development as well as CSCW researchers of the specific elements that make these friendships possible.

\section{ACKNOWLEDGMENTS}

Sincerest thank you to Dr. Gregory Leazer, Dr. Leah Lievrouw, Dr. Safiya Noble, and Dr. Kim Gomez for their guidance, mentorship, feedback, and support throughout this project. Thank you 
as well to the UCLA Department of Information Studies, the UCLA Graduate Division, and Beta $\mathrm{Phi} \mathrm{Mu}$ for their generous funding and support of this work.

\section{REFERENCES}

[1] Ahmad, M. A., Huffaker, D., Wang, J., Treem, J., Kumar, D., Poole, M. S., \& Srivastava, J. (2010). The Many Faces of Mentoring in an MMORPG. 2010 IEEE Second International Conference on Social Computing, 270-275. https://doi.org/10.1109/SocialCom.2010.45

[2] Barman-Adhikari, A., Bowen, E., Bender, K., Brown, S., \& Rice, E. (2016). A Social Capital Approach to Identifying Correlates of Perceived Social Support Among Homeless Youth. Child \& Youth Care Forum, 45(5), 691-708. https://doi.org/10.1007/s10566-016-9352-3

[3] Bowen, G.L., \& Chapman, M.V. (1996). Poverty, Neighborhood Danger, Social Support, and the Individual Adaptation Among At-Risk Youth in Urban Areas. Journal of Family Issues, 17(5).

[4] Bowen, G.L., \& Chapman, M.V. (1996). Poverty, Neighborhood Danger, Social Support, and the Individual Adaptation Among At-Risk Youth in Urban Areas. Journal of Family Issues, 17(5).

[5] boyd, D. (2014). It's Complicated: The Social Lives of Networked Teens. New Haven, CT, USA: Yale University Press.

[6] Cobb. (1976). Social Support as a Moderator of Life Stress. Psychosomatic Medicine, 38(5), 300-314.

[7] Cutrona, C. E., \& Russell, D. W. (1990). Type of social support and specific stress: Toward a theory of optimal matching. ResearchGate. Retrieved from

https://www.researchgate.net/publication/232560583_Type_of_so

cial_support_and_specific_stress_Toward_a_theory_of_optimal_matching

[8] Cutrona, C. E., Russell, D. W., Abraham, W. T., Gardner, K. A., Melby, J. N., Bryant, C., \& Conger, R. D. (2003). Neighborhood context and financial strain as predictors of marital interaction and marital quality in African American couples. Personal Relationships, 10(3), 389-409. https://doi.org/10.1111/14756811.00056

[9] Cutrona, C. E., Russell, D. W., Hessling, R. M., Brown, P. A., \& Murry, V. (2000). Direct and moderating effects of community context on the psychological well-being of African American women. Journal of Personality and Social Psychology, 79(6), 1088-1101.

[10] Dykstra, P., \& Fleischmann, M. (2016). Cross-age friendship in 25 European countries. Studi di sociologia, 54(2), 107-125.

[11] Ellison, N. B. (2007). Social Network Sites: Definition, History, and Scholarship. Journal of ComputerMediated Communication, 13(1), 210-230. https://doi.org/10.1111/j.1083-6101.2007.00393.x

[11] Emerson, R. M., Fretz, R. I., \& Shaw, L. L. (2011). Writing Ethnographic Fieldnotes, Second Edition. University of Chicago Press.istep:

[12] Evans, S., Davis, K., Evans, A., Campbell, J. A., Randall, D. P., Yin, K., \& Aragon, C. (2017). More Than Peer Production: Fanfiction Communities As Sites of Distributed Mentoring. Proceedings of the 2017 ACM Conference on Computer Supported Cooperative Work and Social Computing, 259-272. https://doi.org/10.1145/2998181.2998342

[13] Fields, D. A., Pantic, K., \& Kafai, Y. B. (2015). "I Have a Tutorial for This": The Language of Online Peer Support in the Scratch Programming Community. Proceedings of the 14th International Conference on Interaction Design and Children, 229-238. https://doi.org/10.1145/2771839.2771863

[14] Cobb. (1976). Social Support as a Moderator of Life Stress. Psychosomatic Medicine, 38(5), 300-314.

[15] Ford, D., Lustig, K., Banks, J., \& Parnin, C. (2018). “We Don’T Do That Here”: How Collaborative Editing with Mentors Improves Engagement in Social Q\&A Communities. Proceedings of the $2018 \mathrm{CHI}$ Conference on Human Factors in Computing Systems, 608:1-608:12. https://doi.org/10.1145/3173574.3174182 
[16] Herr-Stephenson, S., Rhoten, D., Perkel, D., \& Sims, C. (2011). Digital Media and Technology in Afterschool Programs, Libraries, and Museums. Retrieved November 7, 2016, from MIT Press website: https://mitpress.mit.edu/books/digital-media-and-technology-afterschool-programs-libraries-andmuseums

[17] Jenkins, H. (2006). Convergence Culture: Where Old and New Media Collide. NYU Press.

[18] Kaplan, A. M., \& Haenlein, M. (2010). Users of the world, unite! The challenges and opportunities of Social Media. Business Horizons, 53(1), 59-68. https://doi.org/10.1016/j.bushor.2009.09.003

[19] Kids at Risk. (n.d.). Retrieved April 4, 2019, from https://www.bgca.org/kids-in-need/kids-at-risk

[20] Leung, L. (2007). Stressful Life Events, Motives for Internet Use, and Social Support Among Digital Kids. CyberPsychology \& Behavior, 10(2), 204-214. https://doi.org/10.1089/cpb.2006.9967

[21] Leung, L. (2011). Loneliness, social support, and preference for online social interaction: the mediating effects of identity experimentation online among children and adolescents. Chinese Journal of Communication, 4(4), 381-399. https://doi.org/10.1080/17544750.2011.616285

[22] Leung, L., \& Lee, P. S. N. (2005). Multiple determinants of life quality: the roles of Internet activities, use of new media, social support, and leisure activities. Telematics and Informatics, 22(3), 161-180. https://doi.org/10.1016/j.tele.2004.04.003

[23] Lofland, J., \& Lofland, L. (1995). Analyzing Social Settings: A Guide to Qualitative Observation and Analysis. Belmont, CA: Wadsworth.

[24] Magee, R. M., Agosto, D. E., \& Forte, A. (2017). Four Factors That Regulate Teen Technology Use in Everyday Life. Proceedings of the 2017 ACM Conference on Computer Supported Cooperative Work and Social Computing, 511-522. https://doi.org/10.1145/2998181.2998310

[25] McConnell, E. A., Birkett, M., \& Mustanski, B. (n.d.). Families Matter: Social Support and Mental Health Trajectories Among Lesbian, Gay, Bisexual, and Transgender Youth. Journal of Adolescent Health. https://doi.org/10.1016/j.jadohealth.2016.07.026

[26] McGrath, B., Brennan, M. A., Dolan, P., \& Barnett, R. (2014). Adolescents and their networks of social support: Real connections in real lives? Child \& Family Social Work, 19(2), 237-248. https://doi.org/http://dx.doi.org/10.1111/j.1365- 2206.2012.00899.x

[27] McMahon, S. D., Felix, E. D., \& Nagarajan, T. (2010). Social Support and Neighborhood Stressors Among African American Youth: Networks and Relations to Self-Worth. Journal of Child and Family Studies, 20(3), 255-262. https://doi.org/10.1007/s10826-010-9386-3

[28] Murthy, D. (2013). Twitter: Social Communication in the Twitter Age. John Wiley \& Sons.

[29] Paulsen, V., \& Berg, B. (2016). Social support and interdependency in transition to adulthood from child welfare services. Children and Youth Services Review, 68, 125-131. https://doi.org/10.1016/j.childyouth.2016.07.006

[30] Smith, A. B., \& Inder, P. M. (1990). The relationship of classroom organisation to cross-age and cross-sex friendships. Educational Psychology, 10(2), 127-140.

[31] Strauss, A., \& Corbin, J. (1990). Basics of Qualitative Research: Grounded Theory Procedures and Techniques (Second Edition edition). SAGE Publications, Inc.

[32] Subrahmanyam, K., Reich, S. M., Waechter, N., \& Espinoza, G. (2008). Online and offline social networks: Use of social networking sites by emerging adults. Journal of Applied Developmental Psychology, 29(6), 420-433. https://doi.org/10.1016/j.appdev.2008.07.003

[33] Washington, T., Rose, T., Colombo, G., Hong, J. S., \& Coard, S. I. (2015). Family- Level Factors and African American Children's Behavioral Health Outcomes: A Systematic Review. Child \& Youth Care Forum, 6(44), 819-834.

Received April 2019; revised June 2019; accepted August 2019. 